\section{Controversies in Therapeutics}

\title{
Anticoagulant drugs in the elderly: valuable in selected patients
}

\author{
G D O Lowe
}

Taken together, venous and arterial thromboembolism form the commonest causes of death, admission to hospital, and physical disability in the second half of life. Their incidence, prevalence, and mortality all increase steeply with age. The mechanisms are not known but may include changes related to age, such as increased concentrations of clotting factors, ${ }^{1}$ increased activation of coagulation and platelets, ${ }^{2}$ decreased fibrinolytic activity, ${ }^{\prime}$ increased immobility and venous stasis in the case of venous thrombosis, increased atherosclerosis in the case of arterial thrombosis, and increased frequency of atrial fibrillation in the case of arterial embolism.

As fibrin is an important component of both venous and arterial thrombi and emboli, anticoagulant drugs, which reduce the formation of fibrin, should be effective in prevention and treatment. Although heparin and oral anticoagulant drugs have been used for over 40 years, proof has been slow in coming owing to the historical inability of doctors to perform adequately controlled trials, ${ }^{1}$ as with many other treatments. Evidence is, however, increasing that anticoagulant drugs are indeed effective in preventing both venous and arterial thromboembolism, thereby reducing both morbidity and mortality. ${ }^{13-11}$

\section{Low doses of anticoagulant treatment in preventing venous thromboembolism}

The prevention of venous thromboembolism in elderly patients is important not only because of their high risk but also because of the increased difficulty in diagnosing pulmonary embolism before death. Fewer than $10 \%$ of patients aged over 70 with fatal pulmonary

Effect on venous thromboembolism and mortality of prophylactic low doses of heparin ( 5000 units every eight to 12 hours subcutaneously) in surgical and general medical trials and acute stroke. Values are incidences (percentages) unless stated otherwise

\begin{tabular}{|c|c|c|c|c|}
\hline Complication & $\begin{array}{l}\text { Group given } \\
\text { heparin }\end{array}$ & $\begin{array}{l}\text { Control } \\
\text { group }\end{array}$ & $\begin{array}{l}\text { Percentage odds } \\
\text { difference }(\mathrm{SD})\end{array}$ & $\mathrm{p}$ Value \\
\hline \multicolumn{5}{|c|}{ Surgical trials ${ }^{3 \star}$} \\
\hline Deep vein thrombosis & 9 & 22 & $-68(3)$ & $<0.001$ \\
\hline Non-fatal pulmonary embolism & 1.4 & $2 \cdot 1$ & $-40(11)$ & $<0.001$ \\
\hline Fatal pulmonary embolism & $0 \cdot 3$ & 0.9 & $-64(15)$ & $<0.001$ \\
\hline Total mortality & $3 \cdot 3$ & $4 \cdot 2$ & -21 & $<0.02$ \\
\hline No of fatal bleeds & 8 & 6 & & NS \\
\hline All bleeds & $6 \cdot 0$ & $3 \cdot 8$ & $+66(11)$ & $<0.001$ \\
\hline \multicolumn{5}{|c|}{ General medical trial $\dagger$} \\
\hline Total mortality & $7 \cdot 8$ & $10 \cdot 9$ & $-31 \neq$ & $0 \cdot 025$ \\
\hline \multicolumn{5}{|c|}{ Acute stroke $\left\|^{8}\right\|$} \\
\hline Deep vein thrombosis & 22 & 73 & -70 & $<0.001$ \\
\hline Pulmonary embolism at necropsy & 29 & 70 & -59 & $<0.01$ \\
\hline Total mortality & $21 \cdot 5$ & 33 & -35 & $<0.05$ \\
\hline
\end{tabular}

*General, urological, and orthopaedic surgery; $n=15598$. Eight hourly and 12 hourly heparin regimens had similar efficacy and risks of bleeding.

$t_{n}=1358$. Heparin given every 12 hours

$\$ 95 \%$ Confidence interval $0 \cdot 2$ to $52 \cdot 3$.

$\| \mathrm{n}=305$. Heparin given every eight hours

embolism had the correct diagnosis established in life. ${ }^{12}$

An overview of the randomised controlled trials in general, orthopaedic, and urological surgery found that heparin at low doses (5000 units every eight to 12 hours subcutaneously) was highly effective in reducing venous thromboembolism and mortality (table). ${ }^{3}$ The mean age of patients in these trials was high (60-80). The proportional reductions in risk of thrombosis were similiar in the different types of trials, hence the absolute benefits may be greatest in patients at highest risk - for example, elderly patients and patients having hip operations. ${ }^{3}$ Although the risk of bleeding was increased by heparin, the absolute excess was small ( $2 \%$; see table) and no increase in fatal bleeding was observed. As there is no good evidence that increased bleeding is related to age heparin at low doses is probably even more cost effective in elderly patients than it is in general. ${ }^{3}$

Elderly patients with hip fractures are at high risk of venous thromboembolism and death, which may be significantly reduced by oral anticoagulant prophylaxis, again at the cost of a small increase in bleeding..$^{45}$ If the logistic problems of control with oral anticoagulant drugs in patients having hip operations are not acceptable to orthopaedic surgeons they may use low doses of heparin. ${ }^{3}$ Other anticoagulant regimens that reduce the risk of deep vein thrombosis after hip operations with minimal risk of bleeding include subcutaneous ancrod, adjusted doses of heparin, and low doses of warfarin ${ }^{6}$ and heparins of low molecular weight. ${ }^{13}$

In patients who are not having operations low doses of heparin significantly reduced the incidence of deep vein thrombosis after myocardial infarction, stroke, heart failure, and chest infection. ${ }^{6}$ A large controlled study of patients with short term illness admitted to general medical wards (of whom over $43 \%$ were aged over 70 ) found that low doses of heparin significantly reduced mortality, according to the principle of "intention to treat" (see table). ' The reduction in mortality was apparent in all age groups, and only one major bleed was reported. Patients with suspected myocardial infarction and stroke were excluded from this study. In a randomised study of elderly patients with acute stroke (mean age 76) low doses of heparin significantly reduced venous thromboembolism and mortality (see table). ${ }^{8}$ The reduced mortality seemed greater in patients with less severe strokes and was not offset by increased bleeding or by increased mortality when patients with pulmonary embolism were excluded. Computed tomography was not performed in this study to exclude the $10 \%$ of patients with haemorrhagic stroke. ${ }^{8}$ Until these results are confirmed the prudent physician should perform computed

continued on page 1262

\section{EDITORIAL COMMENT}

Clear evidence on the ratio of risk to benefit of long term oral treatment with anticoagulant drugs in elderly patients is lacking. Warfarin is potentially a lethal drug, and old people are not good at taking drugs reliably or accurately. For all these reasons I tend to agree with Dr Scott that the outpatient use of anticoagulant drugs in elderly patients should be considered only rarely. The case made by Dr Lowe

is different and highlights the advantages of prophylaxis with anticoagulant drugs in elderly patients when they are clearly at increased risk of thromboembolism. Treatment with low doses of heparin during operations and other times of immobility is of proved value in patients of all ages and may be given under the controlled conditions of a hospital.

PETER RUBIN, professor of therapeutics, University Hospital, Nottingham NG7 2UH
Alasgow Royal

Infirmary, Glasgow

owe, FRCP

consultant physician 


\section{Controversies in \\ Therapeutics}

continued from page 1260 tomography before giving low or high doses of anticoagulant drugs to patients with stroke. ${ }^{6914}$ Newer heparins or heparinoids may also be effective in preventing venous thrombosis after stroke. ${ }^{14}$

These data support the recommendations of the National Institutes of Health consensus development conference that both medical and surgical patients over the age of 40 be given low doses of heparin routinely during their acute immobility to prevent venous thromboembolism unless there are contraindications. Old age is not a contraindication: it is a positive indication as the higher risk should confer a greater cost benefit and reduction in risk.

\section{Full doses of anticoagulant drugs in treating venous and arterial thromboembolism}

Venous thromboembolism-Established venous thromboembolism is largely preventable by low doses of heparin but is still a common problem for physicians and surgeons who neglect prophylaxis, especially in elderly patients in whom diagnosis is more difficult. ${ }^{12}$ As in younger patients clinical diagnosis is unreliable and should be confirmed by objective methods. ${ }^{10}$ Controlled or randomised trials of anticoagulant treatment have been slow in coming, but the overall evidence from recent trials suggests that treatment with heparin and warfarin reduces recurrent thromboembolism. ${ }^{10}$ As with preventive studies the mean age of patients in these trials was high: no evidence was found that anticoagulant drugs were less effective in older patients.

Myocardial infarction - The overall evidence suggests that anticoagulant treatment reduces mortality after myocardial infarction by about a fifth in the short term and long term. ${ }^{1}$ In trials in which anticoagulant drugs were properly controlled long term oral anticoagulant treatment reduced mortality by about half. ${ }^{15}$ The Dutch sixty plus study showed that older patients who were already stable taking oral anticoagulant drugs after myocardial infarction did better if they continued taking them. ${ }^{16}{ }^{17}$ Although physicians may prefer long term prophylaxis with aspirin,$^{18}$ they should still consider short term anticoagulant treatment to prevent venous thrombosis or recurrent coronary thrombosis after thrombolytic treatment. ${ }^{6}$

Cardiac thromboembolism, stroke, and peripheral arterial disease-No adequate controlled trials have been reported in patients with cardiac thromboembolism, stroke, and peripheral arterial disease until recently. ${ }^{19}$ Anticoagulant treatment after cardioembolic stroke seems to be safe in selected patients (particularly when haemorrhage is excluded by computed tomography $\left.{ }^{20}\right)$; a European collaborative study of oral anticoagulant drugs versus aspirin or placebo in patients with atrial fibrillation and previous stroke is in progress. ${ }^{20}$ The reduction in mortality from stroke by low doses of heparin has been noted. ${ }^{8} \mathrm{~A}$ recent randomised controlled trial of oral anticoagulants in patients having femoropopliteal grafting for peripheral arterial disease (of whom $42 \%$ were aged over 65 ) showed significant reduction in mortality. ${ }^{11}$ Further studies of anticoagulants in preventing recurrent arterial thrombosis are required and should include as many elderly patients as possible because they are most at risk.

Risk of bleeding-Although some early studies reported a higher risk of bleeding in older patients given therapeutic intravenous heparin, this was given before the routine use of standardised laboratory monitoring. ${ }^{15}$ In a recent large study of 2656 patients bleeding associated with heparin treatment was not significantly associated with age ${ }^{21}$ Similarly, the largest reported experience of bleeding associated with long term anticoagulant treatment showed no correlation with age. ${ }^{15}$ The risks of bleeding are reduced by

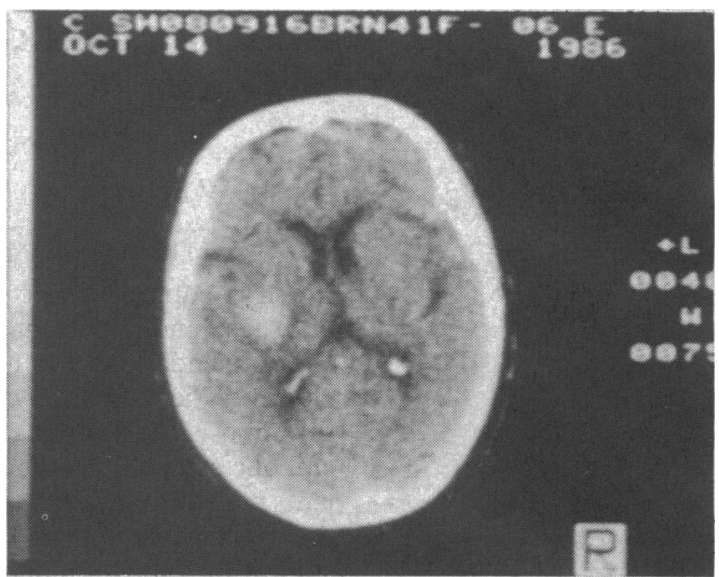

Computed tomogram showing left sided internal capsule haematoma in a patient with right sided hemiparetic stroke

observing contraindications, by giving heparin by continuous infusion rather than as a bolus injection, by standardised monitoring of both heparin and warfarin, by replacing heparin early with oral anticoagulant drugs, and by adopting lower therapeutic ranges for control by oral anticoagulants. ${ }^{10}$ is Age alone is not a contraindication to full dose anticoagulation. It is sensible to recognise that sensitivity to warfarin (receptor affinity) increases with age, requiring a lower dose $^{22}$; that the diseases and drugs which may increase the risks of bleeding are more common in the elderly; and that mental impairment may reduce compliance. Such problems are not, however, confined to the elderly: they also apply to younger alcoholics, ${ }^{21}$ who form an equally large proportion of my general medical patients in Glasgow.

\section{Conclusion}

Anticoagulant drugs reduce the morbidity and mortality from venous and arterial thrombotic disease, especially in older patients who have the highest risk. These benefits are not offset by an increased risk of bleeding.

1 Meade TW, ed. Anticoagulants and myocardial infarction. A reappraisal. Chichester: Wiley, 1984

2 Stewart ME, Douglas JT, Lowe GDO, Prentice CRM, Forbes CD. Prognostic value of beta-thromboglobulin in patients with transient cerebral ischaemia. Lancet 1983;ii:479-82.

3 Collins R, Scrimgeour A, Yusuf S, Peto R. Reduction in fatal pulmonary embolism and venous thrombosis by perioperative administration of subcutaneous heparin. Overview of results of randomized trials in general, orthopedic and urologic surgery. $N$ Engl F Med 1988;318:1162-73.

4 Sevitt S, Gallagher NG. Prevention of venous thrombosis and pulmonary ( phenistione in middle aged and elderly patients with fractured necks phenindione in middle-aged and

5 Morris GK, Mitchell JRA. Warfarin sodium in prevention of deep venous thrombosis and pulmonary embolism in patients with fractured neck of femur. Lancet 1976;ii:869-72.

6 Goldhaber SZ. Prevention of venous thromboembolism. In: Goldhaber SZ ed. Pulmonary embolism and deep venous thrombosis. Philadelphia: WB Saunders, 1985:135-57.

7 Halkin H, Goldberg J, Modan M, Modan B. Reduction of mortality in genera medical inpatients by low-dose heparin prophylaxis. Ann Intern Med 1982;96:561-5.

8 McCarthy ST, Turner J. Low-dose subcutaneous heparin in the prevention of deep-vein thrombosis and pulmonary emboli following acute stroke. Age Ageing 1986;15:84-8.

9 National Institutes of Health. Consensus development conference statement. Prevention of venous thrombosis and pulmonary embolism. $\mathcal{F} A M A$ 1986;256:744-9.

10 Anonymous. Management of venous thromboembolism [Editorial]. Lancet $1988 ; i: 275-7$

11 Kretschmer G, Wenzl E, Schemper $M$, et al. Influence of postoperative anticoagulant treatment on patient survival after femoropopliteal vein bypass surgery. Lancet 1988;i:797-9.

12 Goldhaber SZ, Hennekens CH, Evans DA, et al. Factors associated with correct antemortem diagnosis of major pulmonary embolism. Am $\mathfrak{I}$ Med 1982;73:822-6.

13 Turpie AGG, Levine MN, Hirsh J, et al. A randomized controlled trial of a low molecular weight heparin (enoxaparin) to prevent deep vein thrombosis in patients undergoing elective hip surgery. N Englf Med 1986;315:925-9.

14 Turpie AGG, Levine MN, Hirsh J, et al. Double-blind randomised trial of Org 10172 low-molecular-weight heparinoid in prevention of deep-vein throm bosis in thrombotic stroke. Lancet 1987;i:523-6. 
15 Loeliger EA, Van Dijk-Wierda CA, Van den Besselaar HP, Broekmans AW, Roos J. Anticoagulant control and the risk of bleeding. In: Meade TW, ed. Anticoagulants and myocardial infarction. A reappraisal. Chichester: Wiley, 1984:135-77.

16 Sixty Plus Reinfarction Study Research Group. A double-blind trial to assess long-term oral anticoagulant therapy in elderly patients after myocardial infarction. Lancet 1980;ii:989-94.

17 Sixty Plus Reinfarction Study Research Group. Risks of long-term oral anticoagulant therapy in elderly patients after myocardial infarction. Lance $1982 ; 1: 64-8$.

18 Antiplatelet Trialists' Collaboration. Secondary prevention of vascular disease by prolonged antiplatelet treatment. $\mathrm{Br}$ Med $\mathcal{F}$ 1988;296:320-31.
19 Lowe GDO. Anticoagulants in cardiac thromboembolism, cardiac surgery, peripheral arterial disease and cerebrovascular disease. In: Meade TW, ed. Anticoagulants and myocardial infarction. A reappraisal. Chichester: Wiley, 1984:203-21

20 Lodder J, Dennis MS, Van Raak L, Jones LN, Warlow CP. Cooperative study on the value of long term anticoagulation in patients with stroke and nonrheumatic atrial fibrillation. $\mathrm{Br} \mathrm{Med} \mathcal{F}$ 1988;296: 1435-8.

21 Walker AM, Jick H. Predictors of bleeding during heparin therapy. JAMA $1980 ; 244: 1209-12$.

22 O'Malley K, Stevenson IH, Ward CA, Wood AJ, Crooks J. Determinants of anticoagulant control in patients receiving warfarin. $\mathrm{Br} \mathcal{F}$ Clin Pharmacol 1977;4:309-14.
Peter J W Scott

continued from page 1261 simply forget instructions about the dose and the risks. Access to anticoagulant clinics may be difficult, especially as most elderly patients need to be taken in an ambulance. Consideration should be given to alternative treatment such as mobilisation and wearing compression stockings for deep vein thrombosis.

The common practice of diagnosing deep vein thrombosis and pulmonary embolism on clinical evidence alone $e^{35}$ is unacceptably inaccurate..$^{9112021}$ If, however, an elderly patient is suspected of having a massive pulmonary embolism there is certainly an argument to give anticoagulant drugs initially, if there are no contraindications. The diagnosis should then be confirmed by angiography or less invasively by a lung scan, preferably with ventilation enhancement. ${ }^{1923}$ Anticoagulants should be discontinued when a scan shows negative results. In patients whose scans show a positive or even equivocal result continuing anticoagulant treatment depends on clinical judgment. If warfarin is prescribed there seems to be no advantage in continuing for longer than four weeks ${ }^{36}$ and probably not after discharge from hospital.

With the increased risk of bleeding with anticoagulants in the elderly there is a clear ethical need for fully reported studies of the prevention and treatment of thromboembolism and embolic stroke.

1 Caird FI, Scott PJW. Drug induced diseases in the elderly: a critical survey of the literature. Amsterdam: Elsevier, 1986.

2 Jick H, Slone D, Borda IT, Shapiro S. Efficacy and toxicity of heparin in relation to age and sex. $N$ Engl $\mathcal{F}$ Med 1968;279:284-6.

3 Husted S, Andreasen F. Problems encountered with long term treatment with anticoagulants. Acta Med Scand 1976;200:379-84.

4 Coon WW, Willis PW. Hemorrhagic complications of anticoagulant therapy. Arch Intern Med 1974;133:386-92.

5 Wilson JE, Bynum LJ, Parkey RW. Heparin therapy in thromboembolism Am F Med 1981;70:808 16.

6 Kelton JG, Hirsh J. Bleeding associated with antithrombotic therapy. Semin Haematol 1980;17:259-91

7 Wintzen AR, de Jonge H, Loeliger EA, Bots GTAM. Risk of intracerebral hemorrhage during oral anticoagulant treatment: a population study. Ann Neurol 1984;16:553-8.

8 Kottke BA. Disorders of the blood vessels. In: Pathy MSJ, ed. Principles and practice of genatric medicine. Chichester: Wiley, 1985:419-56.

9 Busby W, Bayer A, Pathy J. Pulmonary embolism in the elderly. Age Ageing 1988; 17:205-9.

10 Wessler S. Anticoagulants in the prevention of embolic stroke. Geriatrics 1987:42:29-35.

11 Ramsey LE. Impact of venography on the diagnosis and management of deep venous thrombosis. Br Med f 1983;286:698-9.
12 Whitehouse $\mathrm{G}$. Radiological diagnosis of deep vein thrombosis. Br Med $\mathcal{J}$ 1987;295:801-2.

13 Browse N. Diagnosis of deep vein thrombosis. Br Med Bull 1978;34:163-7.

14 McCarthy ST, Turner J. Low-dose subcutaneous heparin in the prevention of deep-vein thrombosis and pulmonary emboli following acute stroke. $A g e$ Ageing 1986;15:84-8.

15 Turpie AGG, Levine MN, Hirsh J, et al. Double blind radomised trial of Or 10172 low-molecular weight heparinoid in prevention of deep-vein throm bosis in thrombotic stroke. Lancet 1987; i:523-6.

16 Collins R, Scrimgeour A, Yusef S, Peto R. Reduction in fatal pulmonary embolism and venous thrombosis by perioperative administration of subcutaneous heparin. Overview of results of randomized trials in genera orthopaedic and urologic surgery. $N$ Engl $\mathcal{F}$ Med 1988;318:1162-73.

17 Sue-Ling H, Johnston D, McMahon MJ, Philips PR, Davies JA. Pre operative identification of patients at high risk of deep venous thrombosi after elective major abdominal surgery. Lancet 1986;i:1173-6.

18 Lowe GDO, Osborne DH, McCardle BM, et al. Prediction and selective prophylaxis of venous thrombosis in elective gastrointestinal surgery. Lance 1982;i:409-12.

19 Ruckley CV. Management of pulmonary embolism. BrMed f 1982;285:831-3.

20 Egermayer P. Value of anticoagulants in the treatment of pulmonary embolism: a discussion paper. $f R$ Soc Med 1981;74:675-81.

21 Menzoian JO, Williams LF. Is pulmonary angiography essential for the diagnosis of acute pulmonary embolism? Am f Surg 1979;137:543-8

22 Windebank WJ. Diagnosing pulmonary thromboembolism. Br Med $\mathcal{J}$ 1987;294:1369-70.

23 Anonymous. Management of venous thromboembolism [Editorial]. Lancet 1988;i:275-7.

24 Lagerstedt CI, Olsson C-G, Fagher BO, Oqvist BW, Albrechtsson U. Need for long-term anticoagulant treatment in symptomatic calf-vein thrombosis. Lancet 1985 ;ii:515-8.

25 Fagher B, Lundh B. Heparin treatment of deep venous thrombosis. Effects and complications after continuous or intermittent heparin administration. Acta Med Scand 1981;210:357-61.

26 Hull R, Hirsh J, Jay R, et al. Different intensities of oral anticoagulant therap in the treatment of proximal vein thrombosis. N Engl f Med 1982;307: 1676-81.

27 Wolf PA, Abbott RD, Kannel WB. Atrial fibrillation: a major contributor to stroke in the elderly. The Framingham Study. Arch Intern Med 1987;147: $1561-4$

28 Wilson DB. Chronic atrial fibrillation in the elderly: Risks vs. benefits of long-term anticoagulation. $\mathcal{F}$ Am Geriatr Soc 1985;33:298-302.

29 Lodder J, Dennis MS, Van Raak L, Jones LN, Warlow CP. Cooperative study on the value of long term anticoagulation in patients with stroke and nonon the value of long term anticoagulation in patients with

30 Cerebral Embolism Study Group. Immediate anticoagulation of embolic stroke. Brain hemorrhage and management options. Stroke 1984:15:779-89.

31 Sandercock P, Warlow C, Bamford J, Peto R, Starkey I. Is a controlled trial of long-term oral anticoagulants in patients with stroke and non-rheumatic atrial fibrillation worthwhile? $L$ ancet 1986; ; 788-92.

32 Shepherd AMM, Hewick DS, Moreland TA, Stevenson IH. Age as determinant of sensitivity to warfarin. Br f Clin Pharmacol 1977;4:315-20.

33 Sixty Plus Reinfarction Study Research Group. Second report. Risks of long term oral anticoagulant therapy in elderly patients after myocardia infarction. Lancet 1982;i:64-8.

34 Standing Advisory Committee for Haematology of the Royal College of Pathologists. Drug interaction with coumarin derivative anticoagulants. BrMed f 1982;285:274-5.

35 Prentice AG, Lowe GDO, Forbes CD. Diagnosis and treatment of venous thromboembolism by consultants in Scotland. Br Med f 1982;285:630-2.

36 Holmgren K, Andersson G, Fagrell B, et al. One month versus six month therapy with oral anticoagulants after symptomatic deep venous thrombosis. Acta Med Scand 1985;218:279-84

\section{ANY QUESTIONS}

\section{How effective is laser endarterectomy, and how widely used is the technique?}

Lasers have been used in arterial surgery experimentally and in clinical practice, principally in techniques with microvascular anastomosis and recanalisation of atherosclerotic vessels. In microvascular anastomosis spot welds can be made joining small vessels of $1 \mathrm{~mm}$ or less in diameter or by coagulating collagen or blood around the weld to act as a support.

With blocked arteries in arteriosclerosis it has been shown that atherosclerotic plaque can be vaporised with various lasers, a technique that is especially effective when the plaque is mainly composed of cholesterol. Calcified plaque is more difficult to remove. The technique differs from endarterectomy, when plaque and occluding thrombus are removed surgically.

Several clinical studies have been made using neodymium yttrium aluminium garnet (YAG) or argon lasers to recanalise occluded femoral arteries. The failure rate seems higher than that of surgical methods either because of failure to vaporise calcified plaque or because of immediate thrombosis. Perforation of the artery is the main complication; the effect of vaporised plaque debris on the peripheral vascular bed seems to be minimal but may depend on the quantity of plaque treated.

So far the results do not compare favourably with established methods of treatment by surgery or, indeed, by balloon angioplasty. There may, however, be a place for a combination of percutaneous laser treatment with balloon angioplasty, with the obvious advantage that patients do not need to have surgery. - JOHN M EDWARDS, consultant surgeon, Surrey

Quigley MR, Bailes JE, Kwan HC, et al. Microvascular anastomosis using the milliwatt laser Lasers Surg Med 1985;5:357-65.

Abela GS, Normann S, Cohen D, et al. Effects of carbon dioxide, Nd:UAG, and argon lase radiation on coronary atherosclerotic plaques. Am $\mathcal{F}$ Cardiol 1982;50:1199-205.

Dixon JA. Current laser applications in general surgery. Ann Surg 1988;207:355-71. 